\title{
AVALIAÇÃO DO INCÔMODO SONORO DEVIDO A EXPOSIÇÃO AO RUÍDO AERONÁUTICO NO ENTORNO DO AEROPORTO DE BRASÍLIA
}

\author{
E. B. Carvalho Jr, W. A. Shiguti, A. de Barros, A. M. Maroja, J. M. Shimoishi, W. C. \\ Melo, S. L. Garavelli
}

\begin{abstract}
RESUMO
O presente trabalho avaliou o incômodo sonoro percebido por comunidades expostas ao ruído aeronáutico no entorno do Aeroporto de Brasília. Para tanto, foi elaborado um mapa acústico e um questionário foi aplicado para avaliação da reação das comunidades expostas ao ruído aeronáutico. Os resultados indicaram um nível de incômodo elevado ao ruído aeroviário. Além disso, foi obtido que o ruído aeronáutico e rodoviário interfere significativamente na realização de atividades cotidianas dos pesquisados, tais como estudar, dormir, assistir TV, falar ao telefone e meditar. Essa interferência ocorre tanto no período diurno quanto no noturno. Os respondentes apresentaram significativos níveis de incômodo com o ruído aeronáutico sendo que quanto maior a faixa etária maior o nível de incômodo. Por fim, quando o respondente é despertado durante à noite o nível de incômodo é elevado sendo os pesquisados do sexo feminino mais incomodados.
\end{abstract}

\section{INTRODUÇÃO}

A contaminação acústica é um dos principais efeitos negativos provocados pela operação de um sítio aeroportuário. O ruído pode desencadear déficits crônicos no sono das pessoas, bem como contribuir para a degradação da qualidade de vida, impactar o sono, comprometer o desempenho cognitivo e afetar o equilíbrio emocional das pessoas provocando sensações de irritação, raiva, frustação e medo (Babisch, 2002; WHO, 2011).

O ruído aeronáutico também exerce influência negativa na percepção de bem-estar e satisfação das pessoas que residem em uma determinada região da cidade (Kroesen, M. et al., 2010). Isso contribui para desenvolvimento de conflitos entre os principais atores envolvidos em áreas de aeroportos, ou seja, operadores, governos locais e comunidade (Faburel, 2005; De Barros, 2013).

O ruído das aeronaves tornou-se um dos principais problemas relacionados à atividade aeroportuária, pois comunidades expostas podem desencadear reações capazes de ocasionar importantes restrições à capacidade operacional, à expansão e até à construção de novos aeroportos (De Barros, 2013; Sadr MK et al., 2014). Do exposto, fica destacada a importância de se realizar estudos capazes de satisfazer não só a demanda pelo transporte aéreo, mas também viabilizar o desenvolvimento de medidas que minimizem o impacto do ruído na saúde e na qualidade de vida das comunidades expostas. Para tanto, torna-se imprescindível diagnosticar quais os efeitos adversos causados pelo ruído sobre as comunidades afetadas. No caso, o incômodo é amplamente aceito como a base para se 
avaliar a reação de comunidades expostas, não só ao ruído aeronáutico, mas a qualquer ruído ambiente (WHO, 2011).

Desse modo, o presente trabalho avaliou o incômodo sonoro percebido por comunidades expostas ao ruído aeronáutico no entorno do Aeroporto de Brasília. Para tanto, foi elaborado um mapa acústico e aplicou-se um questionário para avaliação da reação das comunidades expostas ao ruído aeronáutico.

\section{MÉTODO}

Neste estudo, o método é sustentado em modelagens, com elaboração de mapas acústicos, e avaliação do incômodo sonoro.

\subsection{Caracterização do Aeroporto}

O aeroporto objeto de estudo foi o Aeroporto Internacional de Brasília (Figura 1), cuja sigla ICAO (International Civil Aviation Organization) é SBBR.

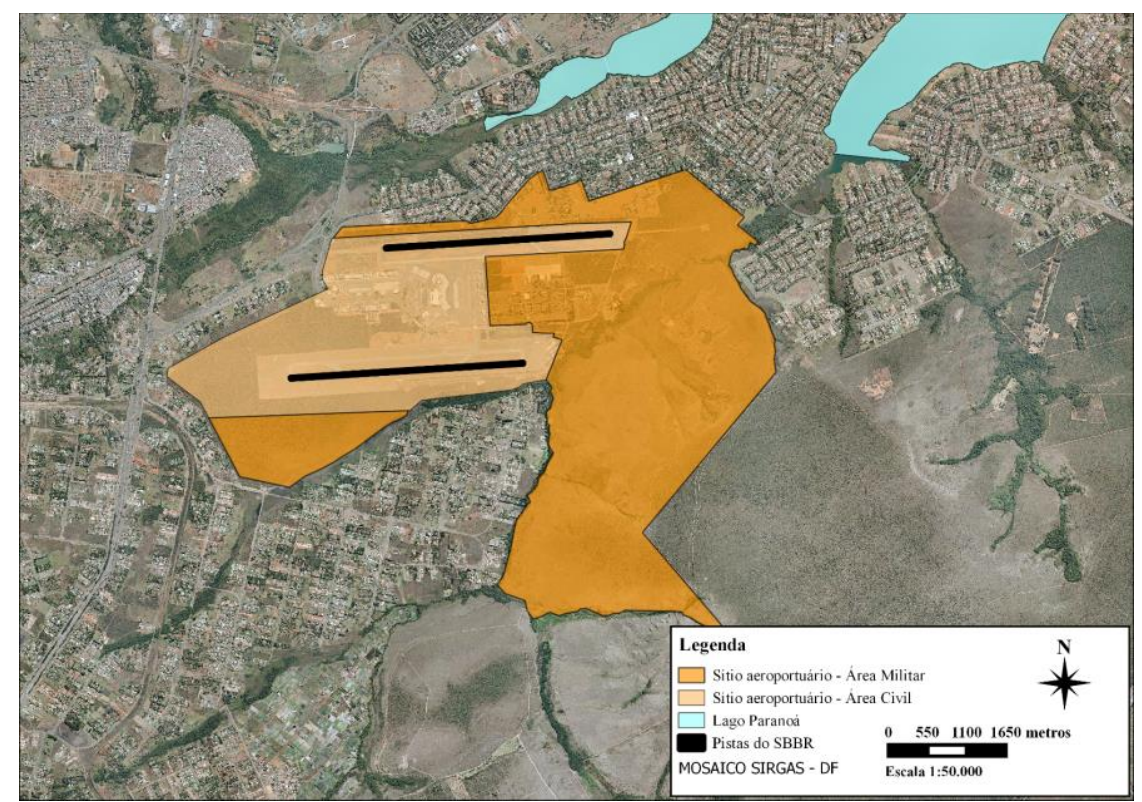

Fig. 1 Mapa de Localização do SBBR

Atualmente, o SBBR é o segundo aeroporto em movimentação de aeronaves e de passageiros no Brasil e devido sua localização geográfica, recebe e distribui mais de 500 voos por dia, sendo considerado ponto de conexão para destinos em todo o país, e no exterior.

\subsection{Mapas Acústicos}

Foram realizadas simulações para a elaboração das curvas de ruído, na métrica acústica DNL (day-night level), com uso do software INM 7.0d. Após essas simulações, o output gerado foi exportado, para um software de Sistema de Informação Geográfica onde os mapas acústicos foram elaborados seguindo a metodologia descrita no RBAC 161 (2013). Para a simulação, vários dados de entradas foram considerados, entre eles: elevação, velocidade média anual do vento, temperatura média anual de referência etc. Esses dados 
foram obtidos em fontes oficiais do governo ou com a própria empresa operadora do SBBR. As curvas de ruído geradas representam a operação do SBBR para 2012 onde foram estimadas 202.000 operações anuais, de pousos e decolagens, e uma média de 553 movimentos diários.

\subsection{Questionários}

Nesse estudo, foi adotada a metodologia internacional de avaliação da reação das comunidades expostas, a uma determinada fonte de ruído ambiente (Fields et al., 2001; ISO, 2003). O \% AI (pessoas altamente incomodadas) foi utilizado para avaliar a relação dose-resposta devido à exposição ao ruído aeronáutico. Os participantes deveriam responder posicionando o seu grau de incômodo numa escala de Likert de 11 pontos (escala de incômodo) com os limites: 0 para nada incomodado e 10 para extremamente incomodado. A escolha pela escala numérica de 11 pontos é baseada no pressuposto de que os respondentes estão mais cognitivamente familiarizados com a escala $0-10$ que com escalas numéricas mais curtas de 7 ou 9 pontos (ISO, 2003). Já o $D N L$ e o L den foram utilizados como indicadores acústicos. Após a definição da escala de incômodo, o termo $\%$ AI é definido como a parte superior (27\% -28\%) da escala de incômodo (EC, 2002).

O questionário elaborado continha perguntas sobre: dados pessoais, incômodo percebido, interferências na vida diária e nível de sonolência diurna. $\mathrm{O}$ instrumento continha sete perguntas relacionadas ao incômodo percebido, devido ao tráfego rodoviário, aeroviário e de outras fontes de ruído (trens, motocicletas, carros de som e construções). Essas são questões de cunho sócio-acústicas, ou seja, pretendem avaliar o grau de incômodo percebido pelos habitantes das regiões pesquisadas. Também apresenta questões relacionadas com as interferências em atividades cotidianas. A opção, de também avaliar o incômodo do tráfego rodoviário, deve-se ao fato dessa fonte de ruído ser a que mais expõem pessoas aos efeitos prejudiciais do ruído no Comunidade Europeia (WHO, 2011).

O questionário foi aplicado por meio on-line sendo enviado por e-mail. Para tanto, foi utilizado o software de questionários on-line SurveyMonkey. O questionário foi estruturado nesse software e um link foi criado para ser enviado aos respondentes. Depois de redigido o questionário, foi realizado um pré-teste com a aplicação de 50 instrumentos. Os dados desses questionários foram analisados, questões foram corrigidas e outras foram eliminadas. O tamanho da amostra foi de 402 indivíduos e para a análise foram realizadas Correlações de Pearson (r), Spearman $(\rho)$ e Testes Qui-quadrados entre as variáveis. Também foi obtido o nível de significância de cada correlação (p), e tabelas de distribuição de frequências foram elaboradas.

\section{RESULTADOS}

A Figura 2 mostra o mapa acústico e a localização das seguintes Regiões Administrativas do Distrito Federal (RA's): Núcleo Bandeirante, Taguatinga, Park Way (SMPW - Setor de Mansões Park Way), Águas Claras, Lago Sul, Jardim Botânico, Candangolândia, Samambaia e Riacho Fundo I. Para auxílio na interpretação dos mapas de ruído deve-se observar a Tabela 1 que expressa os limites para o indicador de ruído $D N L$ bem como a área de cada curva de ruído.

Na Figura 2 é possível visualizar um grande adensamento populacional no interior das curvas compreendidas nos limites $50<\mathrm{DNL} \leq 60$. Residentes no interior dessas curvas, 
principalmente na DNL 60, sentem-se altamente incomodados com o ruído aeroviário (Carvalho Jr et al., 2012; Carvalho Jr, 2015).

\section{Tabela 1 Indicador Acústico DNL e Área Simulada}

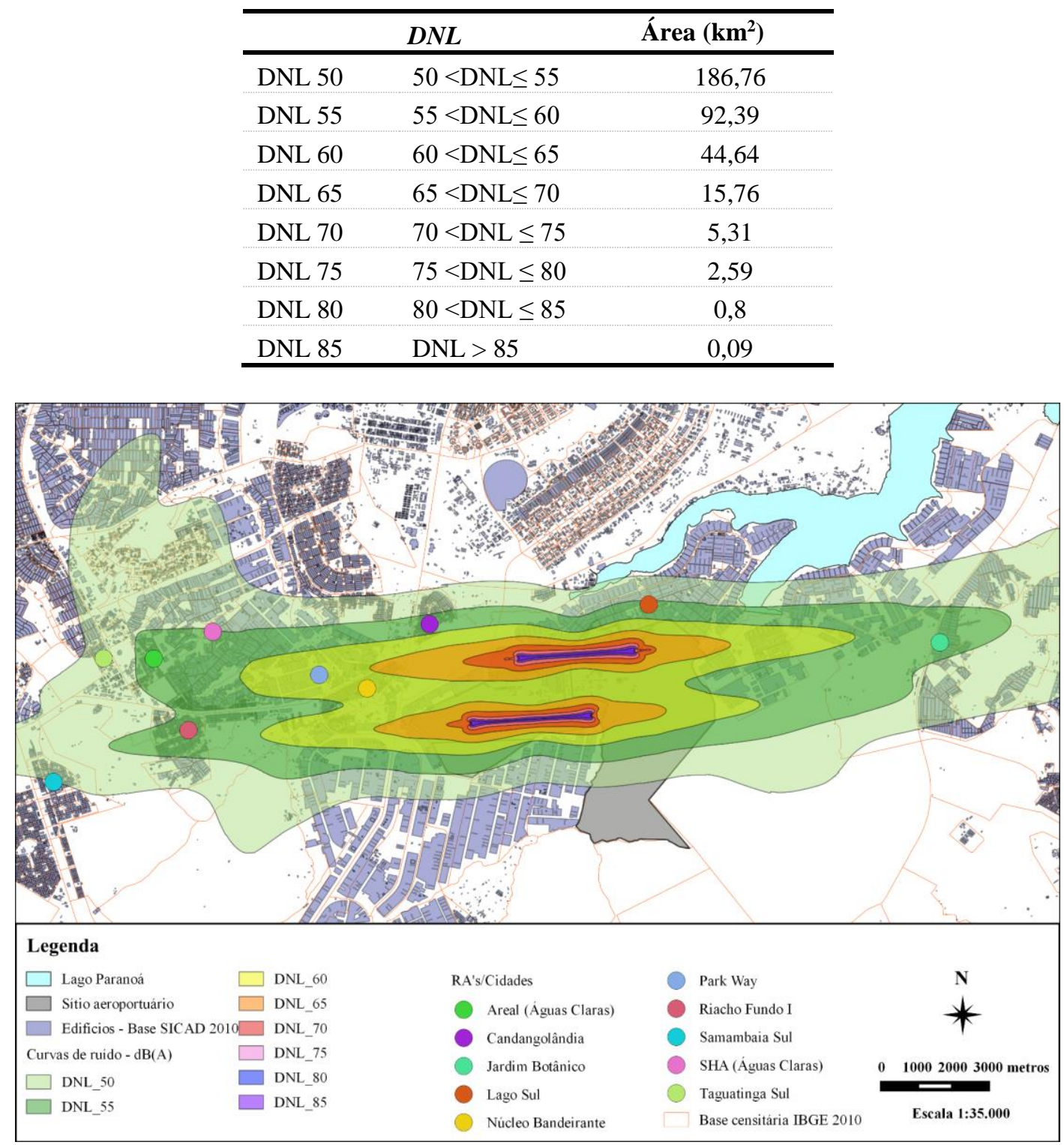

Fig. 2 Localização das RA's entre as Curvas de Ruído Simuladas

Com relação ao questionário, sua confiabilidade foi medida por meio do teste alfa $(\alpha)$ de Cronbach. Os alfas obtidos para as variáveis do questionário foram: níveis de incômodo com fontes sonoras $(\alpha=0,800)$, nível de incômodo com ruído aeronáutico $(0,902)$ e nível de incômodo com ruído rodoviário $(0,919)$. Desse modo, o questionário apresentou valores para o alfa de Cronbach satisfatórios indicando adequada confiabilidade para a análise dos resultados.

No total, $51 \%$ dos pesquisados eram do sexo feminino e $49 \%$ do sexo masculino. A idade dos respondentes ficou assim distribuída: 18 - 20 anos (21\%), 21 - 30 (47\%), 31 - 40 (17\%), 41 - $50(9 \%)$ e $51-60$ anos $(6 \%)$. Quanto à escolaridade, $1 \%$ possui ensino fundamental, $15 \%$ ensino médio, $66 \%$ ensino superior e $18 \%$ indicaram possuir pós- 
graduação. Desse modo, a amostra é composta predominantemente de pessoas jovens, com menos de 30 anos, e com escolaridade elevada. Quanto às residências possuírem algum tipo de isolamento acústico, 93\% responderam que "não" e 7\% "sim". Com relação ao tipo do imóvel: $38 \%$ eram casas com somente pavimento térreo, $26 \%$ casas com dois pavimentos, $7 \%$ casas como mais de dois pavimentos e $29 \%$ apartamentos.

Os respondentes, em todas as faixas etárias, apresentaram consideráveis níveis de incômodo com o ruído das fontes pesquisadas. Cabe destacar que os pesquisados que indicaram como resposta o " 0 " foram classificados como "Nada Incomodados (NI)", 1, 2,3, 4 e 5 como "Pouco Incomodados (PI)", 6 e 7 como "Incomodados (I)" e 8, 9 e 10 como "Altamente Incomodados (AI)". Os respondentes, em todas as faixas etárias, apresentaram consideráveis níveis de incômodo com o ruído das fontes pesquisadas.

Para o ruído aeronáutico, foi verificado um percentual significativo de respondentes I e AI com destaque para Lago Sul (40\%), Núcleo Bandeirante (43\%), Riacho Fundo (45\%) e Park Way (46\%). Além disso, foi verificada uma associação expressiva $(p=0,004)$ entre o nível de incômodo e o ruído aeroviário indicando que a percepção de incômodo ocorre de forma diferente nas RA's analisadas. É o caso, por exemplo, dos elevados \%I e $\%$ AI observados no Riacho Fundo e Taguatinga Sul $(50<D N L \leq 55)$. Essas RA's apresentam consideráveis percentuais de populações expostas ao ruído aeronáutico, nas $D N L$ 's 50 e 55, e estão sob a principal rota de pouso que utiliza a pista 1 do SBBR (cabeceiras 11L - 29R). Em 2014, 66\% das operações de pouso foram realizadas na cabeceira 11L e 45,3\% da operação total (pousos e decolagens) ocorreram na pista 1.

Para o ruído rodoviário todas as RA's apresentaram consideráveis percentuais de incomodados. De forma geral, nota-se que os pesquisados se sentem mais altamente incomodados (AI) com o ruído do tráfego rodoviário do que com o ruído aeronáutico. Cabe ressaltar, que existe uma tendência do aumento do nível de incômodo com o ruído rodoviário em Brasília, pois além dos congestionamentos, que já são comuns nos horários de pico, o crescimento acelerado da frota de veículos provoca acréscimo nos níveis de ruídos (Garavelli et al., 2014).

Para o ruído proveniente de trens, obteve-se percentuais de incomodados nas cidades Núcleo Bandeirante (14\%), Samambaia Sul (7\%), SHA: I (14\%), Park Way (13\%) e Taguatinga Sul (8\%). No Núcleo Bandeirante e no Park Way a linha férrea passa muito próxima às residências em alguns locais. Já Samambaia Sul, SHA, Park Way e Taguatinga Sul são atravessadas por linhas do Metrô - DF. Foi verificada uma associação entre o nível de incômodo e o ruído proveniente dos trens, pois o valor $p(0,049)$ mostrouse altamente significativo indicando que a percepção de incômodo ocorre de forma diferente nas RA's analisadas. O impacto do ruído de trens ainda é pouco estudado no DF. No entanto, Garavelli e Oliveira (2007) avaliaram os níveis ruídos emitidos pelo metrô do DF, em Águas Claras, constatando que os níveis de pressão sonora emitidos pela operação do metrô estão acima do limite imposto pela legislação vigente (NBR 10.151 (ABNT, 2000).

Quanto ao ruído das motocicletas, todas as RA's apresentaram expressivos percentuais de nível de incômodo com o ruído das motocicletas, com destaque para Jardim Botânico (86\%), Samambaia Sul (64\%), Park Way (50\%) e Taguatinga Sul (63\%). Esses resultados mostram que o ruído proveniente das motocicletas apresenta incômodo significativo. Isso se deve, geralmente, pela prática da troca do escapamento original das motocicletas por 
escapamentos chamados esportivos ou pelo uso de escapamentos sem o silenciador.

Para a fonte de ruído carros de som, todas as RA's apresentaram expressivos percentuais de incomodados com o ruído dos carros de som. Também se constatou uma relação altamente significativa entre o nível de incômodo e o ruído dos carros de som $(p=0,000)$ indicando uma diferença na percepção de incômodo entre as RA's. O ruído proveniente de carros de som também vem sendo pouco estudado no DF. Todavia, Ribeiro et al. (2005) quantificaram os níveis de ruído emitidos por carros de som no DF e constataram que os valores medidos ultrapassaram os níveis permitidos pela legislação em todas as áreas estudadas. Concluíram que esta atividade é inviável sob ponto de vista ambiental, pois contribuem de forma expressiva para o aumento da contaminação acústica das cidades, além de prejudicar o conforto da população em geral.

Com relação ao ruído das construções, todas as RA's apresentaram significativos percentuais de nível de incômodo com o ruído das construções. Foi verificada uma associação altamente significativa entre o nível de incômodo e o ruído das construções $(p$ $=0,000$ ) indicando uma diferença na percepção de incômodo entre as RA's. Maroja e Garavelli (2011) realizaram um estudo para estimar e simular o nível de pressão sonora (NPS) emitido durante os estágios de uma obra na construção civil na cidade de Águas Claras. Como resultados obtiveram que os NPS gerados pelas construções estão acima do limite estabelecido pela NBR 10.151 (ABNT, 2000) e pela Legislação Distrital (DF, 2008) mostrando a necessidade da inclusão do tema ruídos nos estudos de impactos ambientais causados pela construção civil.

A Tabela 2 indica o percentual de incomodados, por $D N L$, em relação ao ruído aeronáutico. Como esperado, o percentual de incomodados para as curvas mais ruidosas ( $D N L 60$ e $D N L 65$ ) é maior do que paras as curvas menos ruidosas ( $D N L 50$ e $D N L 55$ ). Foi verificado que $62 \%$ dos respondentes na DNL 65 encontram-se incomodados (I) e altamente incomodados (AI), $36 \%$ na $D N L 60,30 \%$ na $D N L 55$ e $22 \%$ na $D N L 50$. Cabe ressaltar, que na curva $D N L 65$ o percentual de AI é 4 vezes maior do que na $D N L 50$. O $\chi^{2}(9) \operatorname{com} p=0,001$ indica a existência de uma associação altamente significativa entre o nível de incômodo e as $D N L$ 's, ou seja, o nível de incômodo é percebido de forma diferente pelos respondentes nas diferentes RA's.

Tabela 2 Nível de Incômodo com o Ruído Aeronáutico para cada DNL

\begin{tabular}{|c|c|c|c|c|c|c|}
\hline \multirow{2}{*}{ NII } & \multicolumn{3}{|c|}{$D N L$} & \multirow{2}{*}{$\begin{array}{l}\text { \% do } \\
\text { Total }\end{array}$} & \multirow{2}{*}{$\chi^{2}(\mathbf{9})$} & \multirow{2}{*}{$\begin{array}{c}\rho \text { de } \\
\text { Spearman }\end{array}$} \\
\hline & 50 & 55 & 60 & & & \\
\hline NI & $16 \%$ & $18 \%$ & $13 \%$ & $15 \%$ & & \\
\hline PI & $63 \%$ & $53 \%$ & $51 \%$ & $53 \%$ & 28,456 & 0,226 \\
\hline I & $13 \%$ & $18 \%$ & $13 \%$ & $16 \%$ & $p=0,001$ & $p=0,000$ \\
\hline AI & $9 \%$ & $12 \%$ & $23 \%$ & $16 \%$ & & \\
\hline
\end{tabular}

Nota: NI: Nada Incomodado / PI: Pouco Incomodado / I: Incomodado

AI: Altamente Incomodado / NII: Nível de incômodo

A Tabela 3 mostra os resultados do nível de incômodo causado pelo ruído aeronáutico, em algumas atividades cotidianas. De forma geral, nas regiões mais ruidosas ( DNL $60-$ 65) os percentuais de incomodados e altamente incomodados com o ruído aeronáutico, quando estão realizando as atividades mencionadas, são maiores do que nas regiões sob as curvas menos ruidosas ( $D N L 50$ - 55). Ainda foi verificada a existência de correlações 
positivas, moderadas e altamente significativas $(p=0,000)$ entre os níveis de incômodo na realização de atividades diárias, com os níveis de ruído aeronáutico. Desse modo, se os níveis de ruído aeronáutico aumentam o nível de incômodo também se eleva na realização dessas atividades do dia-a-dia.

Tabela 3 Nível de Incômodo com o Ruído Aeronáutico em Atividades Cotidianas

\begin{tabular}{|c|c|c|c|c|}
\hline \multirow[b]{2}{*}{ Atividades cotidianas } & \multirow[b]{2}{*}{ NII } & \multicolumn{3}{|c|}{ Ruído aeronáutico } \\
\hline & & $\begin{array}{c}D N L 50-55 \\
\mathrm{n}=288\end{array}$ & $\begin{array}{c}D N L 60-65 \\
\mathrm{n}=114\end{array}$ & $\chi^{2}(3)$ \\
\hline \multirow{2}{*}{ lendo/estudando } & $\begin{array}{c}\mathrm{I} \\
\mathrm{AI}\end{array}$ & $\begin{array}{l}15 \% \\
27 \%\end{array}$ & $\begin{array}{l}17 \% \\
32 \%\end{array}$ & \multirow{2}{*}{$\begin{array}{c}1,54 \\
0,674^{*}\end{array}$} \\
\hline & $\rho$ & $\begin{array}{c}0,586 \\
0,000^{*}\end{array}$ & $\begin{array}{c}0,430 \\
0,000^{*}\end{array}$ & \\
\hline \multirow{2}{*}{ assistindo TV } & $\begin{array}{c}\mathrm{I} \\
\mathrm{AI}\end{array}$ & $\begin{array}{l}13 \% \\
21 \%\end{array}$ & $\begin{array}{l}13 \% \\
38 \%\end{array}$ & \multirow{2}{*}{$\begin{array}{l}13,09 \\
0,040^{*}\end{array}$} \\
\hline & $\rho$ & $\begin{array}{c}0,548 \\
0,000^{*}\end{array}$ & $\begin{array}{c}0,581 \\
0,000^{*}\end{array}$ & \\
\hline \multirow{2}{*}{ falando ao telefone } & $\begin{array}{c}\mathrm{I} \\
\mathrm{AI}\end{array}$ & $\begin{array}{l}16 \% \\
23 \% \\
\end{array}$ & $\begin{array}{l}14 \% \\
44 \% \\
\end{array}$ & \multirow{2}{*}{$\begin{array}{l}19,52 \\
0,000^{*}\end{array}$} \\
\hline & $\rho$ & $\begin{array}{c}0,564 \\
0,000^{*}\end{array}$ & $\begin{array}{c}0,567 \\
0,000^{*} \\
\end{array}$ & \\
\hline \multirow{2}{*}{ dormindo } & $\begin{array}{c}\mathrm{I} \\
\mathrm{AI}\end{array}$ & $\begin{array}{c}6 \% \\
20 \% \\
\end{array}$ & $\begin{array}{c}6 \% \\
26 \% \\
\end{array}$ & \multirow{2}{*}{$\begin{array}{c}1,56 \\
0,067^{*}\end{array}$} \\
\hline & $\rho$ & $\begin{array}{c}0,388 \\
0,000^{*}\end{array}$ & 0,366 & \\
\hline \multirow{2}{*}{ meditando/rezando/orando } & $\begin{array}{c}\mathrm{I} \\
\mathrm{AI}\end{array}$ & $\begin{array}{l}10 \% \\
21 \%\end{array}$ & $\begin{array}{l}10 \% \\
18 \%\end{array}$ & \multirow{2}{*}{$\begin{array}{c}3,17 \\
0,366^{*}\end{array}$} \\
\hline & $\rho$ & $\begin{array}{c}0,479 \\
0,000^{*}\end{array}$ & $\begin{array}{c}0,382 \\
0,000^{*}\end{array}$ & \\
\hline
\end{tabular}

Nota: NI: Nada Incomodado / PI: Pouco Incomodado / I: Incomodado

AI: Altamente Incomodado / NII: Nível de incômodo / * valor $p$ / $\rho=$ correlação de Spearman

A Figura 3 expressa os resultados do nível de incômodo, onde o percentual de "incomodados" foi somado com o percentual de "altamente incomodados" causado pelo ruído aeronáutico e rodoviário. Nota-se que os níveis de incômodo com o ruído rodoviário e aeronáutico, apresentam-se aproximados para as atividades relacionadas ao estudo, meditar/rezar/orar, falar ao telefone e assistir TV. Entretanto, para a atividade "dormindo" os pesquisados mostram-se muito mais incomodados com o ruído do tráfego rodoviário (44\%) do que para o ruído do tráfego aeroviário (28\%).

De forma geral, os resultados apontados na Figura 2 são corroborados por resultados de outros estudos. Lam et al. (2008) obtiveram que o ruído aeronáutico incomoda fortemente atividades rotineiras, como dormir, assistir TV e concentrar-se. Schreckenberg et al. (2010) concluíram que ruído aeronáutico provoca incômodo relativamente elevado e também está correlacionado com distúrbios em atividades diárias realizadas no interior das residências ou no exterior.

Já Carvalho Jr et al. (2012) consideram o ruído rodoviário e aeronáutico capazes de interferir significativamente no processo de comunicação, na concentração em atividades de escrita e leitura, no sono, além de provocar sobressaltos (sustos). Já Nunes e Ribeiro (2008) afirma que o ruído do tráfego rodoviário compromete a qualidade de vida e o bem- 
estar da população, pois, gera incômodo e interfere na realização de atividades básicas e rotineiras.

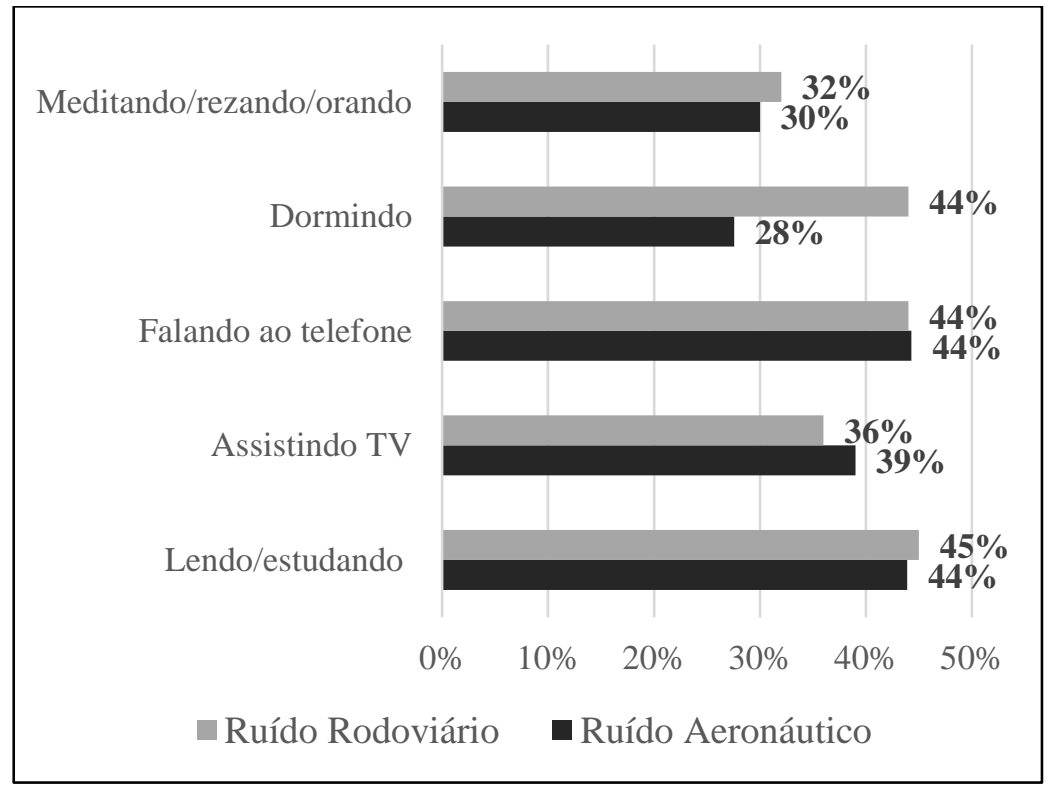

\section{Fig. 3 Nível de Incômodo Causado pelo Ruído Aeronáutico e Rodoviário nas Atividades Cotidianas em Cidades Próximas do SBBR}

Os pesquisados também responderam o quanto o ruído proveniente dos aviões os incomodavam durante o dia e à noite. A Tabela 4 mostra os resultados obtidos para as curvas mais ruidosas (DNL $60-65)$ e menos ruidosas (DNL 50-55). Verifica-se que o percentual de incomodados (AI) com o ruído aeronáutico nas $D N L$ 's 60 e 65 foi maior no período diurno do que no noturno. Para a curva $D N L 50$ - 55 o nível de AI foi um pouco superior no período noturno $(21 \%)$ do que no diurno (18\%). As correlações $(\rho)$ obtidas são positivas, moderadas e altamente significativas $(p=0,000)$ apresentando maiores correlações para o período diurno. Assim, se os níveis de ruído aeronáutico aumentam os níveis de incômodo também aumentam, tanto no período diurno quanto no noturno.

\section{Tabela 4 Nível de Incômodo por Período}

\begin{tabular}{|c|c|c|c|c|}
\hline \multirow[b]{2}{*}{ Período } & \multirow[b]{2}{*}{ NII } & \multicolumn{3}{|c|}{ Ruído aeronáutico } \\
\hline & & $\begin{array}{c}D N L 50-55 \\
\mathrm{n}=288\end{array}$ & $\begin{array}{c}D N L 60-65 \\
\mathrm{n}=144\end{array}$ & $\chi^{2}(3)$ \\
\hline \multirow{4}{*}{ Diurno: $07 \mathrm{~h}-22 \mathrm{~h}$} & I & $15 \%$ & $16 \%$ & \multirow{4}{*}{$\begin{array}{c}11,80 \\
0,008^{*}\end{array}$} \\
\hline & AI & $18 \%$ & $33 \%$ & \\
\hline & \multirow[b]{2}{*}{$\rho$} & 0,672 & 0,644 & \\
\hline & & $0,000^{*}$ & $0,000^{*}$ & \\
\hline \multirow{4}{*}{ Noturno: $22 \mathrm{~h}-07 \mathrm{~h}$} & $\mathrm{I}$ & $9 \%$ & $11 \%$ & \multirow{4}{*}{$\begin{array}{c}3,15 \\
0,369^{*}\end{array}$} \\
\hline & AI & $21 \%$ & $27 \%$ & \\
\hline & \multirow[b]{2}{*}{$\rho$} & 0,516 & 0,568 & \\
\hline & & $0,000^{*}$ & $0,000^{*}$ & \\
\hline
\end{tabular}

Nota: NI: Nada Incomodado / PI: Pouco Incomodado / I: Incomodado / AI: Altamente Incomodado / NII: Nível de incômodo / ${ }^{*}$ valor $p / \rho=$ correlação de Spearman 
A Figura 4 mostra o nível de incômodo (resultado da soma dos incomodados com os altamente incomodados) dos respondentes com o ruído aeronáutico, por faixa etária e por período do dia. Nota-se que o nível de incômodo com o ruído aeroviário é maior, durante o período diurno, para os pesquisados com idades entre 18 e 50 anos. Para os respondentes na faixa etária 51 - 60 anos o incômodo no período noturno (40\%) foi maior do que no diurno $(33 \%)$.

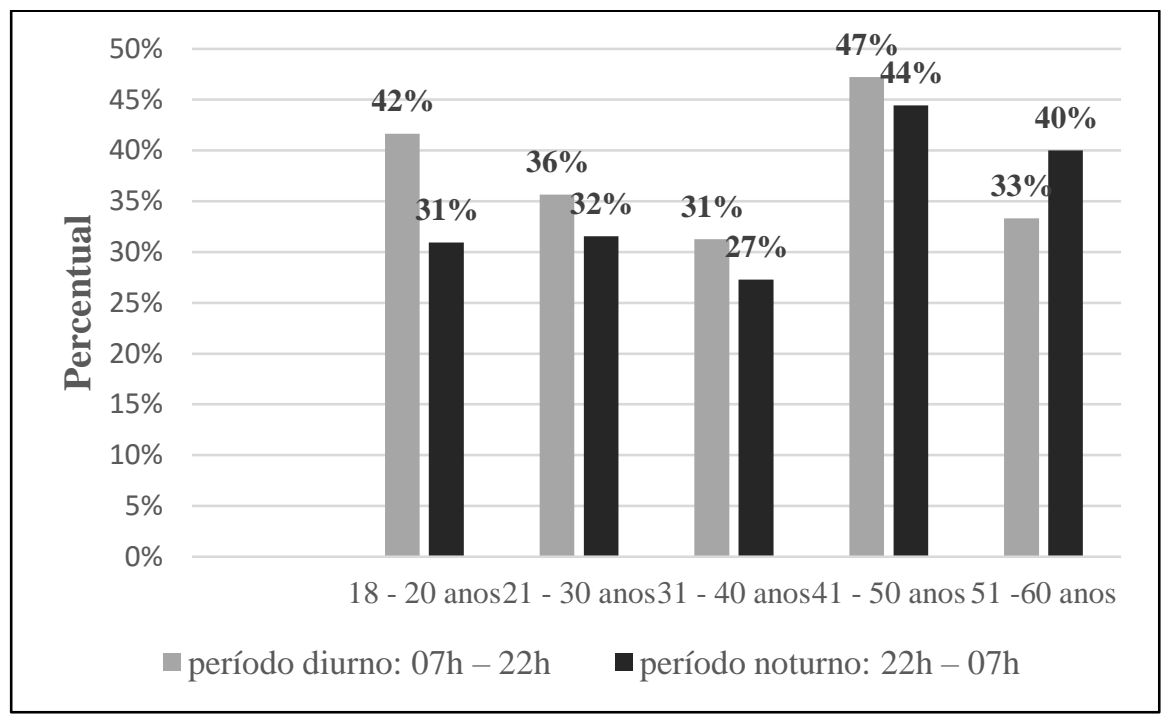

Fig. 4 Nível de Incômodo com o Ruído Aeronáutico por Faixa Etária e por Período do Dia

A Figura 5 mostra o nível de incômodo (resultado da soma dos incomodados com os altamente incomodados) dos respondentes com o ruído rodoviário, por faixa etária e por período do dia.

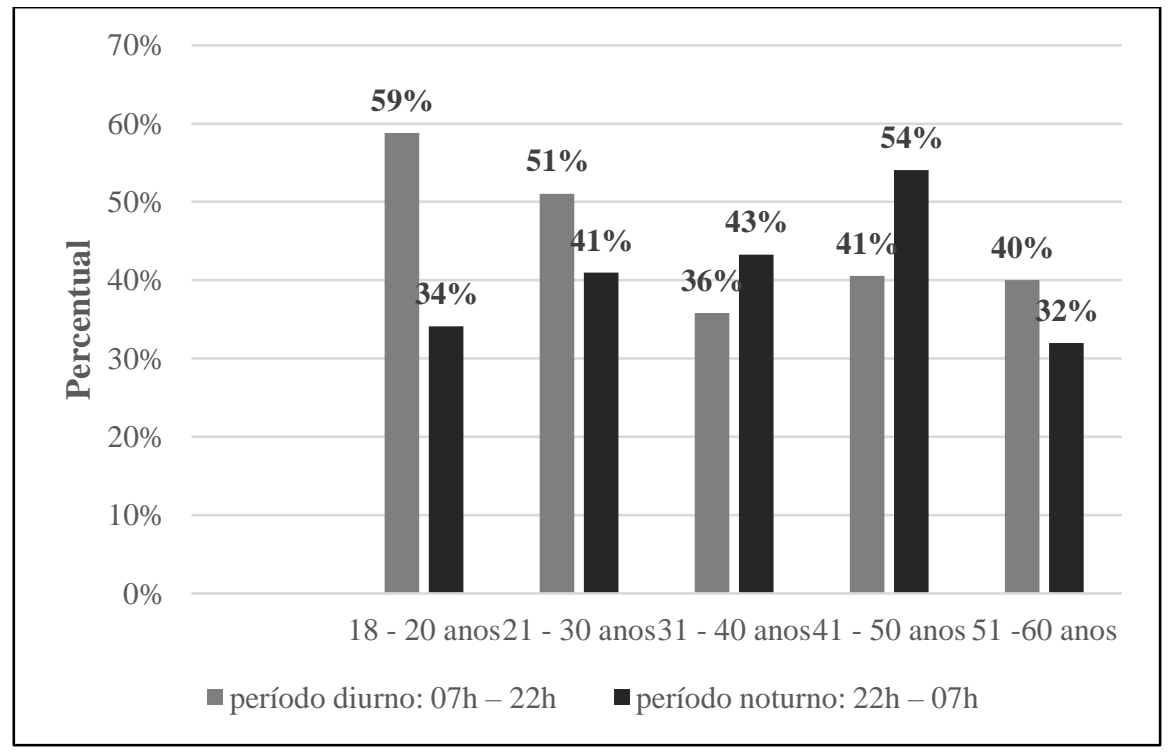

Fig. 5 Nível de Incômodo com o Ruído Rodoviário por Faixa Etária e por Período do Dia

Da Figura 5, verifica-se que o nível de incômodo com o ruído rodoviário é maior, durante o período diurno, para os respondentes com idades entre 18 e 30 anos e na faixa $51-60$ 
anos. Para os respondentes nas faixas etárias $31-40$ e 41 - 50 anos o incômodo no período noturno foi maior do que no diurno (33\%). Comparando as Figuras 4 e 5, observase que nas faixas etárias 18 - 20, 21 - 30 e 31 - 40 anos os percentuais de incômodo com o ruído rodoviário, no período diurno e noturno, são mais elevados do que os percentuais de incômodo indicados para o ruído aeronáutico. Na faixa etária 41 - 50 anos os pesquisados apontaram um nível de incômodo com o ruído aeronáutico (47\%), no período diurno, maior do que o nível de incômodo com o ruído rodoviário (41\%). No período noturno os respondentes mostraram-se mais incomodados com o ruído do tráfego rodoviário (54\%) do que com o ruído aeronáutico (44\%). Por fim, na faixa 51 - 60 anos o nível de incômodo com o ruído aeroviário (33\%), no período diurno, é menor do que o nível de incômodo com o ruído rodoviário (40\%). Já no período noturno, o nível de incômodo com o ruído aeronáutico é maior (40\%) do que com o ruído rodoviário (32\%).

Em suma, constata-se que os percentuais de incomodados, tanto para o ruído aeroviário quanto para o ruído do tráfego rodoviário, são elevados para o período diurno e noturno. Desse modo, essas fontes de ruído comprometem a qualidade de vida e o bem-estar da população, pois além de gerar incômodo, interfere na realização de atividades cotidianas (Lam et al., 2009; Nunes e Ribeiro, 2008; Carvalho Jr et al., 2012; Carvalho Jr, 2015).

A Tabela 5 expressa as respostas referentes aos pesquisados se sentirem incomodados quando despertos/acordados no meio da noite pelo ruído aeroviário. Para as regiões sob as curvas mais ruidosas (DNL $60-65)$, o percentual total de incomodados e altamente incomodados é de 61\%. Para as regiões sob as curvas menos ruidosas ( $D N L 50-55$ ) o percentual total é de 53\%, ou seja, os respondentes mostraram-se mais incomodados, ao serem despertos pelo ruído aeronáutico, nas regiões sob as curvas $D N L 60-65$. Cabe destacar, que os percentuais de incomodados, nas curvas mais e menos ruidosas, indicam que quando o respondente é despertado o nível de incomodo é elevado.

Tabela 5 Nível de Incômodo Quando Acordado com o Ruído Aeronáutico

\begin{tabular}{c|l|c|c|c}
\hline \multirow{2}{*}{ o(a) acorda/desperta no meio da noite } & NII & $\begin{array}{c}D N L 50-55 \\
\mathrm{n}=288\end{array}$ & $\begin{array}{c}\text { DNL 60-65 } \\
\mathrm{n}=144\end{array}$ & \multirow{2}{*}{$\chi^{2}(3)$} \\
\hline \multirow{2}{*}{ ruído aeronáutico } & $\mathrm{I}$ & $10 \%$ & $15 \%$ & \\
& $\mathrm{AI}$ & $43 \%$ & $46 \%$ & \multirow{3}{*}{$3,47 p=0,325$} \\
\cline { 2 - 4 } & $\rho$ & 0,336 & 0,277 & \\
\hline
\end{tabular}

Nota: NI: Nada Incomodado / PI: Pouco Incomodado / I: Incomodado / AI: Altamente Incomodado / NII: Nível de incômodo / * valor $p / \rho=$ correlação de Spearman

Uma análise de relação cruzada foi realizada entre o sexo dos respondentes e o nível de incômodo com o despertar/acordar com o ruído aeronáutico e rodoviário. Dos pesquisados, $47 \%$ dos homens e $53 \%$ das mulheres indicaram se sentirem altamente incomodados com o ruído aeronáutico quando despertados no meio da noite. Já $40 \%$ dos homens e $60 \%$ das mulheres, ao serem acordados com o ruído do tráfego aeronáutico, sentem-se incomodados. Com relação ao ruído rodoviário, os percentuais de homens e mulheres, que indicaram se sentirem altamente incomodados quando despertados no meio da noite, são os mesmos obtidos para o ruído aeronáutico, ou seja, 47\% para os homens e $53 \%$ para as mulheres. $48 \%$ dos homens e $52 \%$ das mulheres, ao serem despertados com o ruído do tráfego rodoviário, sentem-se incomodados. Sendo assim, os pesquisados do sexo feminino sentem-se mais incomodados que os do sexo masculino quando despertados no meio da noite. 


\section{CONSIDERAÇÕES FINAIS}

A avaliação do incômodo sonoro mostrou que os pesquisados residentes sob as curvas de ruído $D N L$ 50, 55 e 60, indicaram um nível de incômodo elevado com o ruído aeroviário proveniente do Aeroporto Internacional de Brasília. Esse resultado alerta para a necessidade do zoneamento sonoro de aeroportos contemplar curvas além da $D N L 65$ incluindo, principalmente, a $D N L$ 60. No caso desse estudo, na $D N L 60,23 \%$ dos respondentes encontram-se altamente incomodados e $13 \%$ incomodados com o ruído aeroviário. Também foi possível concluir que o ruído aeronáutico e rodoviário interfere significativamente na realização de atividades cotidianas dos pesquisados, tais como estudar, dormir, assistir TV, falar ao telefone e meditar. Essa interferência ocorre tanto no período diurno quanto no noturno. Além do mais, os pesquisados, em todas as faixas etárias, apresentaram consideráveis níveis de incômodo com o ruído aeronáutico sendo que quanto maior a faixa etária maior o nível de incômodo. Por fim, quando o respondente é despertado durante à noite o nível de incômodo é elevado sendo os pesquisados do sexo feminino mais incomodados que os do sexo masculino.

Agradecimentos: À FAP/DF (Fundação de Apoio à Pesquisa do Distrito Federal) pelo financiamento e apoio (Edital 01/2016) à participação nesse evento científico.

\section{REFERÊNCIAS}

ABNT (2000) NBR 10.151 - Avaliação do Ruído em Áreas Habitadas, Visando o Conforto da Comunidade. Associação Brasileira de Normas Técnicas, Rio de Janeiro.

Babisch, W (2002). The Noise/Stress Concept, Risk Assessment and Research Needs. Noise Health, v. 4, n. 16, p. 1-11.

Carvalho Júnior, E. B.; Garavelli, S. L.; Maroja, A. M (2012) Analysis of the effects of aircraft noise in residential areas surrounding the Brasilia International Airport. Journal of Transport Literature; v. 6, n. 4, p. $59-81$.

Carvalho Júnior, E. B (2015) Quantificação do incômodo gerado pelo ruído aeronáutico por meio de modelos dose-resposta. Tese de Doutorado - Universidade de Brasília. Faculdade de Tecnologia. Departamento de Engenharia Civil e Ambiental, 182 p.

De Barros A. G (2013) Sustainable integration of airports into urban planning - a review, International Journal of Urban Sciences, v.17, n. 2, p. $226-238$.

EC (2002) Position paper on dose-response relationships between transportation noise and annoyance. European Comission - EU's Future Noise Policy, WG2 - Dose/Effect. Disponível em: http://ec.europa.eu/environment/noise/pdf/noise_expert_network.pdf Data de acesso: 09 de abril de 2016.

Fields, J. M., Jong, R., Brown, A.L., Flindell, I.H., Gjestland, T., Job, R. F. S., Kurra, S., Lercher, P., Vallet, M., Yano, T., Guski, R., Felscher-Suhr, U e Schumer, R (2001) Standardized General-Purpose Noise Reaction Questions for Community Noise Surveys: Research and a Recommendation. Journal of Sound and Vibration, v. 242, n. 4, p. $641-679$.

Garavelli, S. L., Maroja, A. M., Costa, C.A e Carvalho Júnior, E. B (2014) O projeto de Lúcio Costa para Brasília (DF) e a contaminação acústica. $6^{\circ}$ PLURIS - Congresso Luso-Brasileiro para o Planejamento Urbano, Regional Integrado e Sustentável. Lisboa. Livro de Actas, 2014. 
ISO (2003) Acoustics - Assessment of noise annoyance by means of social and socio-acoustic surveys. International Organization for Standardization. ISO/TS 15.666.

Lam, K., Chan, P-K., Chan, T-C., Au W-H e Hui W-C (2009) Annoyance response to mixed transportation noise in Hong Kong. Applied Acoustics. v. 70, p. 1 - 10.

Maroja, A. M e Garavelli, S. L (2011) Emissão de ruídos de uma obra na construção civil. XI Encontro Nacional de Conforto no Ambiente Construído (ENCAC) e VII Encontro Latino Americano de Conforto no Ambiente Construído (ELACAC). Búzios, Rio de Janeiro. Livro de Atas, 2011.

Nunes, M e Ribeiro, H (2008) Interferências do ruído do tráfego urbano na qualidade de vida: zona residencial de Brasília/DF. Cadernos Metrópoles. v. 19, p. 319 - 338.

RBAC (2013) Regulamento Brasileiro da Aviação Civil (161). Planos de Zoneamento de Ruído de Aeródromos. Aprovado na resolução n. 281, de 10 de setembro de 2013, publicado no Diário Oficial da União de 13 de setembro de 2013, Seção 1, p. 14 - 15.

Ribeiro, B. M. P., Madoz, K. A e Garavelli, S. L (2005) Quantificação dos níveis de ruído emitidos por carros de som no Distrito Federal. $1^{\circ}$ PLURIS - Congresso Luso-Brasileiro para o Planejamento Urbano, Regional Integrado e Sustentável. São Carlos, São Paulo. Livro de Atas, 2005.

Sadr MK., Nassiri P, Hosseini M, Monavari M e Gharagozlou A (2014) Assessment of land use compatibility and noise pollution at Imam Khomeini International Airport. Journal of Air Transport Management, v. 34, p. 49 - 56.

Schreckenberg, D., Meis, M., Kahl, C., Peschel, C e Eikmann, T (2010) Aircraft noise and quality of life around Frankfurt Airport. International journal of environmental research and public health, v. 7, n. 9, p. 3382 - 3405.

WHO (2011) World Health Organization. Burden of disease from environmental noise: Quantification of healthy life years lost in Europe. W.H.O. Regional Office for Europe: Denmark. 